\title{
Clasificación automática de glóbulos rojos en frotis de sangre periférica
}

\section{Automatic classification of red cells in peripheral blood smears}

\author{
Marcela Mejia F¹, Marco Alzate², Javier Rodríguez $\mathrm{V}^{1}$.
}

Forma de citar: Mejía M, Alzate M, Rodríguez J. Clasificación automática de glóbulos rojos en frotis de sangre periférica. Rev Univ Ind Santander Salud. 2016; 48(3): 311-319. DOI: http://dx.doi.org/10.18273/revsal.v48n3-2016005 (c) (1) ()

\section{RESUMEN}

Introducción: El diagnóstico del estado eritrocitario en frotis de sangre periférica es un proceso realizado normalmente de forma manual a partir de observación microscópica, lo cual implica una considerable inversión de tiempo y recursos, además de posibles problemas de subjetividad y dificultad en la reproducibilidad del diagnóstico. Objetivo: Desarrollar una aplicación que permita la clasificación automática de glóbulos rojos en frotis de sangre periférica, de utilidad como herramienta de ayuda diagnóstica. Metodología: Se usaron técnicas de procesamiento de imágenes para segmentar los eritrocitos en las fotografías microscópicas y medir en ellos área, perímetro, solidez, circularidad, excentricidad, textura y dimensión box-counting. Se usó una red neuronal artificial para clasificar los eritrocitos según sus características en siete clases, incluyendo normalidad y seis alteraciones patológicas. La red se entrenó de acuerdo con la clasificación de 262 eritrocitos realizada por un hematólogo experto. Los desarrollos se hicieron en matlab ${ }^{\circledR}$, una poderosa plataforma de computación científica. Resultados: La red escogida alcanza el $97.3 \%$ de aciertos en los datos de validación. Las equivocaciones en la red corresponden a células de dudosa clasificación aún para un experto, por presentar características correspondientes a varias clasificaciones patológicas. Conclusiones: La aplicación desarrollada clasifica de manera rápida y acertada los diferentes tipos de glóbulos rojos presentes en una muestra microscópica de frotis de sangre periférica, siendo de utilidad como herramienta de apoyo diagnóstico.

Palabras clave: Eritrocito, clasificación eritrocitaria, procesamiento de imágenes, red neuronal, glóbulos rojos.

\begin{abstract}
Introduction: The process of erythrocyte classification in peripheral blood smear is normally done manually from microscopic observation. This implies not only a considerable investment of time and resources but also brings potential problems of subjectivity and difficulty in the reproducibility of diagnosis. Objective: To develop an application that allows the automatic classification of red blood cells in peripheral blood smears, as a diagnostic aid
\end{abstract}

1. Universidad Militar Nueva Granada. Bogotá, Colombia

2. Universidad Distrital. Bogotá, Colombia

Correspondencia: Ángela Marcela Mejía. Dirección: Carrera 11 No.101-80. Facultad de Ingeniería Universidad Militar Nueva Granada, correo electrónico: angela.mejia@unimilitar.edu.co. Teléfono: +1 6500000 Ext. 1326. 
tool. Methodology: Image processing techniques were used in order to segment erythrocytes in the microscopic photographs and to measure characteristics as area, perimeter, solidity, circularity, eccentricity, texture and boxcounting dimension. An artificial neural network was used to classify the red blood cells in the images in seven classes, including normal and six pathological changes, according to their characteristics. The network was trained according to the classification of 262 erythrocytes by an expert hematologist. The developments were made in matlab $^{\circledR}$, a powerful scientific computing platform. Results: The chosen network reaches $97.3 \%$ correct in the validation data. Mistakes in the network correspond to cells with various pathological classifications features, which make them difficult to classify even for an expert. Conclusions: The developed application classifies quickly and accurately the different types of red blood cells in a microscopic sample of peripheral blood smear, so it could be useful as a diagnostic support tool.

Keywords: Erythrocyte, classification of red blood cells, neural network, image processing, red cells.

\section{INTRODUCCIÓN}

En el campo de la medicina es usual la utilización de parámetros descriptivos y cualitativos para el establecimiento de diferencias entre normalidad y enfermedad. Tal es el caso del análisis de frotis de sangre periférica, proceso de uso clínico diario que es realizado por un experto a partir del análisis microscópico, con base en características cualitativas basadas en la morfología del eritrocito ${ }^{1,2}$. Así, en general, el eritrocito normal o normocito se identifica como un disco ovalado y bicóncavo que carece de núcleo y de la mayoría de organelos, tiene un diámetro entre seis y ocho $\mu \mathrm{m}$ con una región pálida central de no más de tres $\mu \mathrm{m}$ de diámetro, y tiene una apariencia rojo/naranja bajo el tinte de Wright. Esta forma básica se ve alterada bajo algunas condiciones patológicas particulares. El acantocito, por ejemplo, presenta proyecciones gruesas espaciadas de manera irregular, mientras el equinocito presenta proyecciones más pequeñas y espaciadas regularmente. En el degmacito se pierde una porción semicircular del borde de la célula. El eliptocito es un óvalo más alargado, por lo que también se conoce como ovalocito o célula cigarro. El leptocito (o Codocito) tiene un área central de tinte intenso rodeada por un anillo pálido y, posteriormente, por otro anillo intenso en el borde de la célula, de donde surgen los nombres sugestivos de sombrero mejicano o célula de tiro al blanco. El normoblasto (o eritroblasto) es un glóbulo rojo inmaduro que aún conserva su núcleo, tiene un mayor tamaño y toma un tinte azul/negro. El dacrocito tiene una elongación puntuda, por lo que se conoce también como célula lágrima. El esferocito es excesivamente redondo y carece de la región pálida central. El drepanocito (o célula hoz) tiene forma de cuarto-creciente. El reticulocito es una célula joven excesivamente grande que está en un punto intermedio entre la célula nucleada inmadura y el eritrocito normal, por lo que se aprecian en él las redes reticulares de RNA ribosomal. El estomatocito tiene una palidez central ovalada o rectangular (en forma de boca) debido a la pérdida de concavidad en uno de sus lados. El esquistocito tiene una forma irregular fragmentada y dentada con dos puntos extremos y sin la región central pálida. Por último, cuando las células se agrupan, puede existir una aglutinación en la que se pierden los contornos individuales de las células, o un fenómeno de rollos, en el que las células se superponen unas sobre otras dando la apariencia de monedas apiladas ${ }^{1,3,4}$.

Este tipo de clasificación basada en parámetros descriptivos y cualitativos implica que la clasificación de las muestras se realiza sin criterios cuantitativos de diagnóstico, y sus conclusiones dependen de la pericia y experiencia del evaluador ${ }^{1,3,2}$. Adicionalmente, el hecho de que se realice de manera manual y completamente dependiente del experto, implica una inversión de tiempo y dinero considerable que se podría disminuir si se cuenta con una herramienta automática de clasificación del eritrocito.

Existen interesantes trabajos relacionados en la literatura. Por ejemplo, Mohammed, et al. ${ }^{5}$ ofrecen una revisión exhaustiva de los algoritmos usados en el análisis de imágenes de frotis de sangre periférica (segmentación, extracción y selección de características, clasificación de células y herramientas computacionales utilizadas). Señalan los potenciales resultados positivos de las características morfológicas procesadas mediante redes neuronales, que es el enfoque utilizado en este artículo, pero no mencionan la clasificación de eritrocitos en múltiples clases. Tzanakuo et al. ${ }^{6}$ estimaron características morfológicas de las células para usarlas en un clasificador neuronal que detectaba eritrocitos, leucocitos y plaquetas. 
Aunque la detección de plaquetas fue exitosa, hubo una alta tasa de errores al distinguir eritrocitos de leucocitos. Más recientemente, Khashman ${ }^{7}$ hizo la misma clasificación mediante redes neuronales promediando patrones morfológicos, logrando una tasa de aciertos muy superior. En Bergen, et al. ${ }^{8}$ también distinguieron entre eritrocitos y leucocitos con el fin de facilitar la cuenta del número de cada tipo de células en una imagen. Howard, et al. ${ }^{9}$ y Azali, et al. ${ }^{10}$ hicieron clasificaciones de eritrocitos en dos clases, normales y anormales, utilizando una red neuronal que, en ambos casos, operaba sobre parámetros morfológicos. Gual-Arnau, et al. ${ }^{11}$ usaron geometría integral, contornos activos y la técnica de los $k$ vecinos más cercanos para clasificar los eritrocitos en tres clases: normales, drepanocitos (células hoz) y otras deformaciones. Aunque los resultados de clasificación fueron excelentes para los drepanocitos, más de la mitad de las células con otras deformaciones fueron clasificadas como normales. Ya con anterioridad, Wheeles, et al. ${ }^{12}$ habían obtenido resultados similares

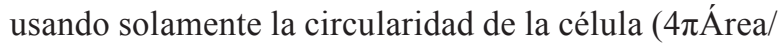
Perímetro ${ }^{2}$ ) Oliveros, et al. ${ }^{13}$ lograron una clasificación semejante en tres clases, pero en vez de células hoz detectaron células elongadas. Poon, et al. ${ }^{14}$ detectaron y segmentaron células nucleadas mediante técnicas estándar de procesamiento de imágenes. Savkare, et al. ${ }^{15}$ presentan un sistema automático para la clasificación de eritrocitos de acuerdo con su estado de infección con el parásito de la malaria. Rezatofighi, et al. ${ }^{16}$ clasifica múltiples clases de leucocitos. Todos estos y muchos otros trabajos semejantes son precedentes importantes para nuestra propuesta, pero el único trabajo que encontramos donde se clasifican múltiples tipos de eritrocitos fue el de Albertini, et al. ${ }^{17}$, donde usan procesamiento de imágenes para extraer algunos parámetros que alimentan un discriminador lineal de siete tipos de eritrocitos. Sorprendentemente, a pesar de usar un discriminador lineal, alcanzaron un $70 \%$ de aciertos. Sin embargo no usaron métodos más elaborados ya que el artículo está orientado sólo al análisis discriminante multivariado.

En este artículo se presenta una aplicación desarrollada en matlab ${ }^{\circledR 18}$ que permite analizar imágenes microscópicas de frotis de sangre periférica humana para establecer una clasificación de los eritrocitos observados a partir de rasgos morfológicos, la cual puede ser utilizada como herramienta de apoyo diagnóstico, no solo para diferenciar normalidad de anormalidad sino para determinar el tipo de anormalidad característica de cada célula observada. Reportamos los aspectos técnicos del análisis de las imágenes y remitimos a dicho artículo para los detalles $^{19}$. En este artículo presentamos los resultados desde el punto de vista de un estudio de pruebas diagnósticas que permitiría disminuir la incertidumbre en la toma de decisiones con base en las anormalidades presentes en los eritrocitos.

\section{METODOLOGÍA}

Para esta investigación se contó con 23 muestras de frotis de sangre periférica, provenientes del Laboratorio de Referencia en Morfología Hematológica. Las muestras fueron tratadas con coloración de Wright y se realizaron fotografías microscópicas de $2700 \times 3600$ pixeles, con 50 pixeles por micrómetro. Las imágenes fueron observadas a través de un microscopio Carl Zeiss, y las imágenes fueron tomadas por una Cámara de microscopio digital. De estas imágenes se pueden distinguir 355 eritrocitos aislados, 265 de los cuales han sido clasificados con precisión por hematólogos expertos. De los quince tipos de células posibles, entre las 265 células clasificadas sin duda, hay tres que aparecen una sola vez (un leptocito, un eritroblasto y un estomatocito), por lo que sólo se usaron 262 células así: siete Dacrocitos, 36 Eliptocitos, 42 Equinocitos, 37 Esferocitos, 20 Esquistocitos, 100 Normocitos y 20 Rollos.

Para el desarrollo de la aplicación, inicialmente se realizó el proceso de segmentación, mediante el cual se aíslan las células de interés de la imagen total. Para esto se llevaron a cabo diferentes procesos como la intensificación del contraste mediante ajustes del histograma de los niveles de luminancia sin alterar el color $^{19,20}$, seguido por un filtrado tipo mediana, el cual reduce el ruido sin afectar los bordes. Sobre esta imagen ajustada se hizo una binarización para distinguir entre las células y el fondo de la imagen usando el método de Otsu ${ }^{19,20}$. Posteriormente se encuentran las regiones conectadas que puedan constituir eritrocitos aislados, rellenando los huecos de dichas regiones para evitar confundir la palidez central con el fondo de la imagen ${ }^{19,20}$. Con las regiones seleccionadas se construye una máscara que permite obtener la imagen segmentada con la información original de los eritrocitos detectados ${ }^{19,20}$. La Figura 1 muestra el resultado del proceso de segmentación a partir de una imagen de entrada en la que se detectaron 19 eritrocitos aislados. 

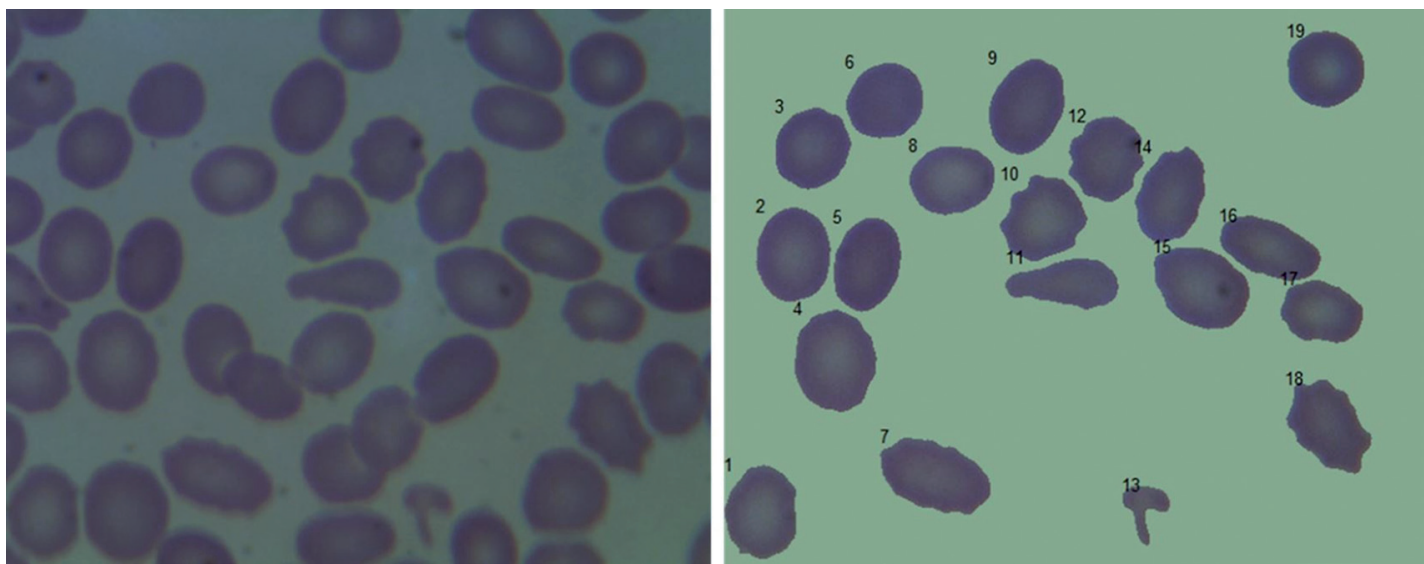

Figura 1. Imagen de entrada y resultado del proceso de segmentación

Una vez detectadas las células de interés dentro de la imagen, el siguiente paso es la extracción de las características de cada una de ellas. Algunas medidas, como el área, el perímetro, la solidez, la circularidad y la excentricidad se pueden obtener directamente de la imagen binarizada. El área se define como el número de pixeles en la región de interés y el perímetro es el número de pixeles en la frontera de la región de interés (los pixeles en contacto con la región clasificada como fondo). Al considerar la envolvente convexa de la célula, se puede calcular la solidez, esto es, la proporción de los pixeles en la célula con respecto a los pixeles en su envolvente convexa. Este parámetro vale uno para células convexas como los esferocitos, pero decrece rápidamente a medida que la envolvente convexa abarca más pixeles de la región del fondo. La excentricidad se obtiene considerando la elipse que tiene el mismo momento de inercia que la región de interés (con respecto al eje perpendicular que atraviesa su centroide) y calculando la relación entre la distancia focal y el eje mayor de dicha elipse. Una excentricidad igual a cero corresponde a un círculo mientras una excentricidad igual a uno corresponde a una línea. Por último, la circularidad se refiere a la relación de proporcionalidad entre el área y el cuadrado del perímetro ${ }^{20}$.

Las siguientes cuatro medidas se refieren a la textura de la célula. La media y la desviación estándar corresponden a las estadísticas de la intensidad de los pixeles de la región de interés y proporcionan una primera aproximación. Sin embargo, se ofrecen otras dos características que refinan esta descripción de la textura de la célula al precisar la variabilidad de dicha intensidad. Una de ellas es la palidez central, que mide el contraste entre el promedio del tono de gris de la zona clara del centro y el promedio del tono de gris en el borde de la célula, como muestra la Figura 2. La otra medida de textura, la dimensión, se refiere a la dimensión boxcounting en 3D de la superficie de la célula ${ }^{21}$. Para calcular esta dimensión consideramos la imagen 2D en tonos de gris como una superficie bi-dimensional en un espacio euclidiano tri-dimensional, donde el nivel de gris corresponde a la tercera dimensión euclidiana.

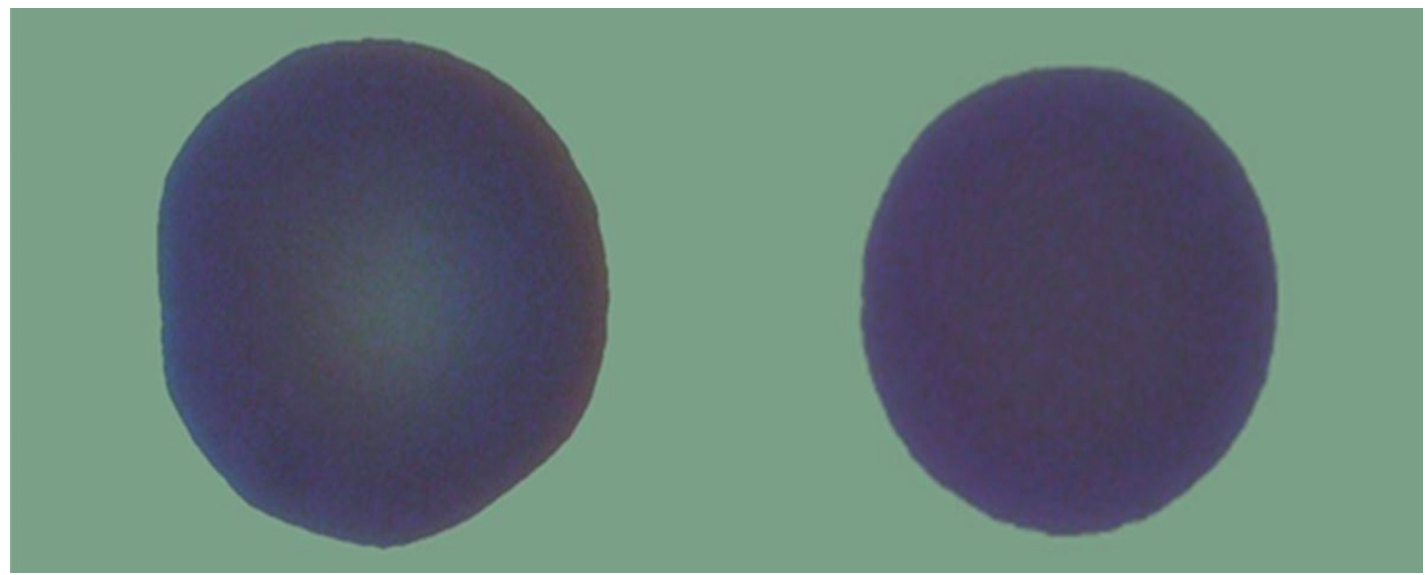

Figura 2. Palidez central en un normocito y en un esferocito 
Se utilizó una red con siete neuronas en la capa de entrada, correspondientes a las características medidas, con excepción de la media y la varianza, pues, como se mencionó, ellas no aportaban ninguna información adicional a la contenida en las siete restantes características. En la capa de salida se dispuso de siete neuronas, correspondientes a cada tipo de célula. Pruebas piloto mostraron que la estructura óptima de la red debía incluir siete neuronas en la capa escondida, pues así se ajustaba la capacidad de aprendizaje de la red con el problema de clasificación propuesto. El proceso de aprendizaje fue el clásico algoritmo de Back-Propagation-Learning ${ }^{22}$, aprovechando la disponibilidad de una base de datos de 23 imágenes con 355 células aisladas en ellas, 262 de las cuales estaban ya clasificadas por un hematólogo experto. Esta base de datos se usó para el proceso de aprendizaje, separando aleatoriamente 150 células de entrenamiento, 50 células de verificación y 62 células de validación. El proceso de aprendizaje se detenía cuando la tasa de aciertos en las muestras de validación dejaba de aumentar, indicando el inicio del sobre-entrenamiento. Después de entrenar así un amplio número de redes con distintas inicializaciones y distintas divisiones de las muestras de entrenamiento, verificación y validación, se escogió la red con mejores resultados en las muestras de validación.

La Figura 3 muestra un diagrama que resume el proceso, desde la imagen de entrada hasta la clasificación de cada célula detectada.

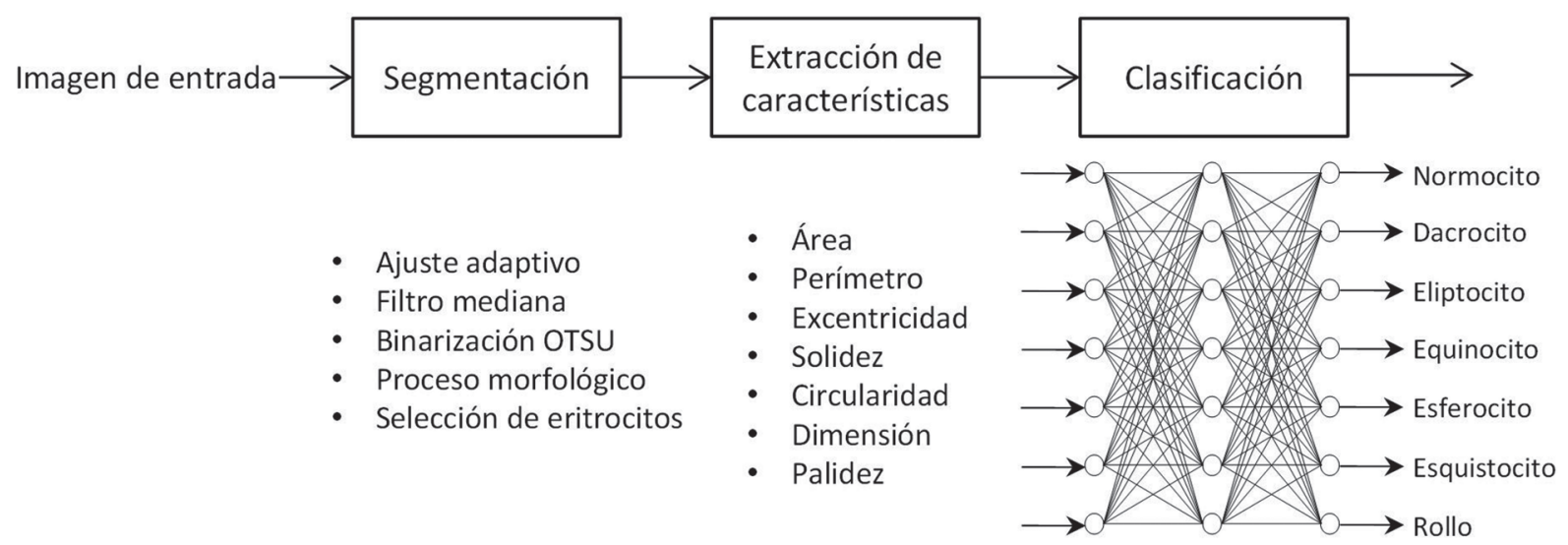

Figura 3. Diagrama del proceso automático de clasificación.

\section{RESULTADOS}

Comparando los rangos de valores característicos de cada tipo de célula para cada una de las características evaluadas, se encontró que algunas de ellas permiten establecer diferencias entre algunos de los tipos de eritrocitos evaluados. Por ejemplo, en la Figura 4 se observa el rango de cada una de las características extraídas de las imágenes, separadas para cuatro tipos de eritrocitos: Normocitos, esferocitos, equinocitos y eliptocitos (presentamos sólo estos cuatro tipos de eritrocitos a manera de ejemplo). Se observa cómo la circularidad es suficiente para distinguir a los esferocitos de los eliptocitos e inclusive de los equinocitos, aunque la solidez constituye una medida más efectiva para distinguir entre esferocitos y equinocitos. Aunque ninguna de ellas permitiría distinguir esferocitos de normocitos, la palidez resulta una característica claramente discriminatoria entre estos dos tipos de células. La excentricidad, a su vez, permite distinguir a los eliptocitos entre los demás tipos de células. Las otras características no resultan tan discriminantes por sí mismas, aunque es notorio que, por ejemplo, el área tiende a ser menor en los eliptocitos que en otras células mientras el perímetro tiende a ser mayor en los equinocitos. Las características de media, desviación y dimensión no resultan tan discriminantes como las características anteriormente descritas.

La Tabla 1 muestra la matriz de confusión del clasificador automático con respecto a la clasificación hecha por los expertos, esto es, muestra la sensibilidad (qué fracción de las muestras positivas clasificó como positivas), la especificidad (qué fracción de las muestras negativas clasificó como negativas), la precisión (qué fracción de las muestras que clasificó como positivas eran realmente positivas) y la exactitud (qué fracción de muestras clasificó correctamente, ya sea como positivas o negativas) ${ }^{23}$. Por ejemplo, todas las 36 células clasificadas por los expertos como eliptocitos fueron clasificadas de la misma manera por la red neuronal, 
y ninguna célula que no haya sido clasificada por los expertos como eliptocito fue clasificada como tal por la red neuronal. Esto quiere decir que, con respecto a los eliptocitos, hubo 36 verdaderos positivos, 226 verdaderos negativos, cero falsos positivos y cero falsos negativos, lo cual indica que tanto la exactitud como la especificidad, la precisión y la sensibilidad de la red fueron del $100 \%$ para los eliptocitos. Sin embargo, de los siete dacrocitos en la base de datos, la red identificó correctamente cinco, confundió uno con un equinocito y confundió otro con un normocito. Esto da una precisión del 83.3\% (5/6), una sensibilidad de 71.4\% (5/7), una especificidad de $99,6 \%(254 / 255)$ y una exactitud de $98,9 \%(259 / 262)$.
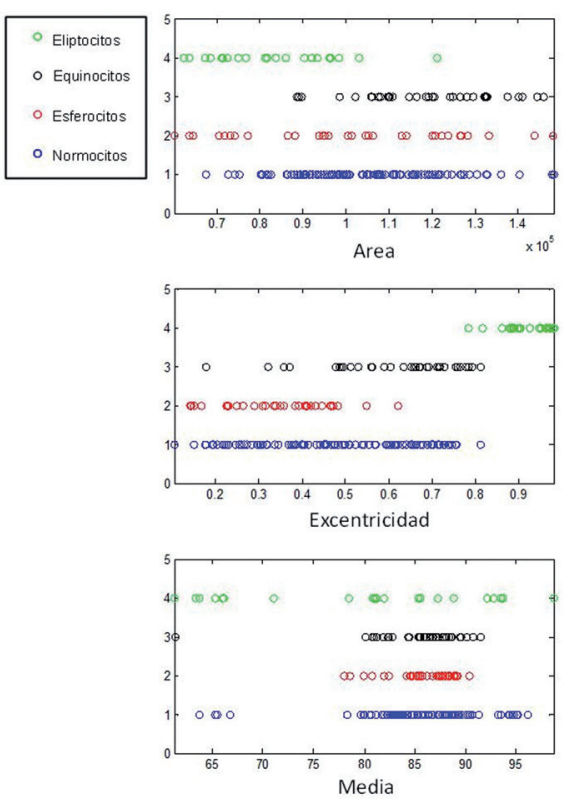
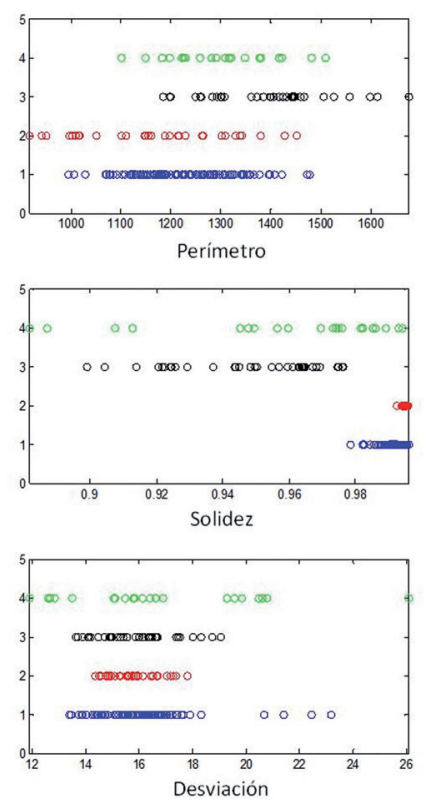
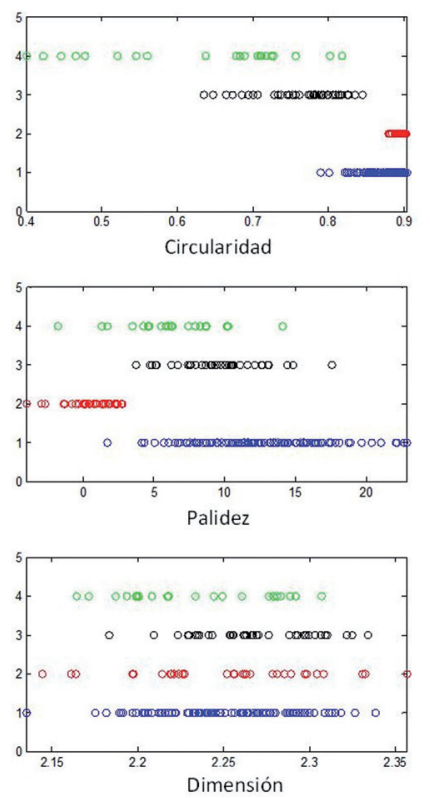

Figura 4. Rangos de las nueve características seleccionadas para cuatro tipos de células.

Tabla 1. Validación del clasificador.

\begin{tabular}{lcccccccc}
\hline $\begin{array}{c}\text { Tipo de } \\
\text { célula }\end{array}$ & $\begin{array}{c}\text { Verdaderos } \\
\text { positivos }\end{array}$ & $\begin{array}{c}\text { Verdaderos } \\
\text { negativos }\end{array}$ & $\begin{array}{c}\text { Falsos } \\
\text { positivos }\end{array}$ & $\begin{array}{c}\text { Falsos } \\
\text { negativos }\end{array}$ & Precisión & Sensibilidad & Exactitud & Especificidad \\
\hline Dacrocito & 5 & 254 & 1 & 2 & $83.3 \%$ & $71.4 \%$ & $98.9 \%$ & $99.6 \%$ \\
Eliptocito & 36 & 226 & 0 & 0 & $100 \%$ & $100 \%$ & $100 \%$ & $100 \%$ \\
Equinocito & 41 & 216 & 4 & 1 & $91.1 \%$ & $97.6 \%$ & $98.1 \%$ & $98.2 \%$ \\
Esferocito & 36 & 225 & 0 & 1 & $100 \%$ & $97.3 \%$ & $99.6 \%$ & $100 \%$ \\
Esquistocito & 19 & 242 & 0 & 1 & $100 \%$ & $95 \%$ & $99.6 \%$ & $100 \%$ \\
Normocito & 99 & 160 & 2 & 1 & $98 \%$ & $99 \%$ & $98.9 \%$ & $98.8 \%$ \\
Rollo & 19 & 242 & 0 & 1 & $100 \%$ & $95 \%$ & $99.6 \%$ & $100 \%$ \\
\hline
\end{tabular}

Los buenos resultados del clasificador con cada una de las células se podría resumir en una tasa total de aciertos de 97.3\% (255/262). Es interesante notar que las equivocaciones de la red también confunden a los expertos y algunas de las equivocaciones son en realidad aciertos parciales. Por ejemplo, la Figura 5 muestra un dacrocito, un equinocito y un eliptocito al lado de una célula que presenta características de los tres tipos de eritrocitos. La red neuronal produce un valor mayor a 0.5 en las tres salidas correspondientes, pero dándole ligeramente más peso al eliptocito, mientras que el hematólogo la clasificó como equinocito. 


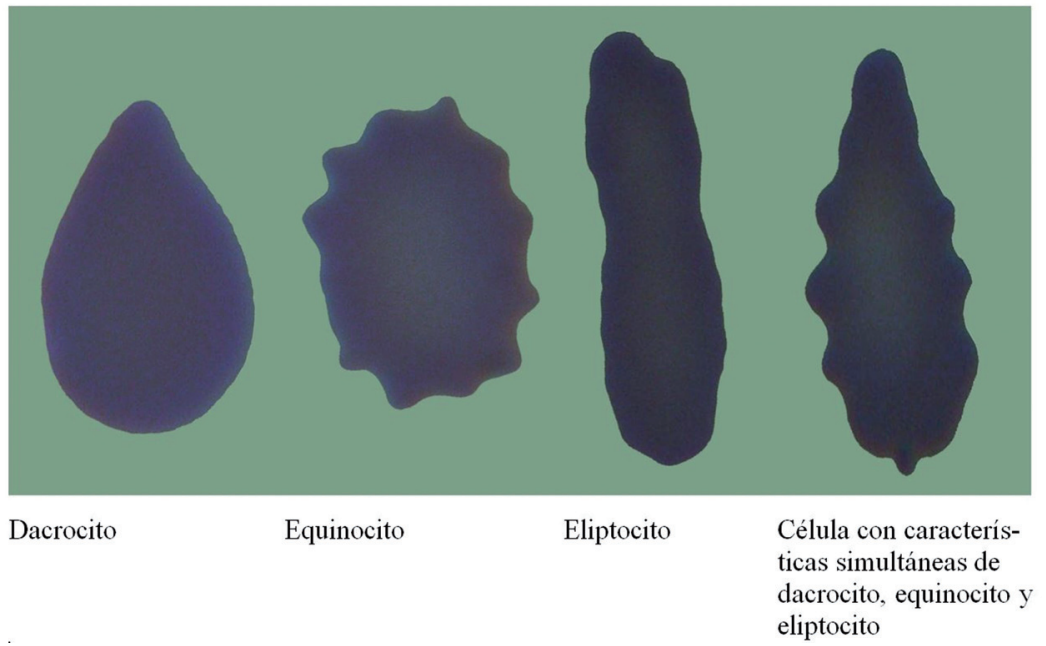

Figura 5. La red activa varios tipos de célula para una misma muestra

\section{DISCUSIÓN}

En el presente trabajo se desarrolló una herramienta de clasificación de apoyo diagnóstico que permite de manera rápida y acertada diferenciar los tipos de glóbulos rojos presentes en una muestra microscópica obtenida mediante frotis de sangre periférica. Para ello se elaboró un método de clasificación que parte del tratamiento digital de imágenes para medir algunas características de los eritrocitos y se usó una red neuronal adecuadamente entrenada para determinar el tipo de eritrocito correspondiente. La Figura 6 muestra la interfaz gráfica de la aplicación desarrollada en matlab $^{\circledR}$.

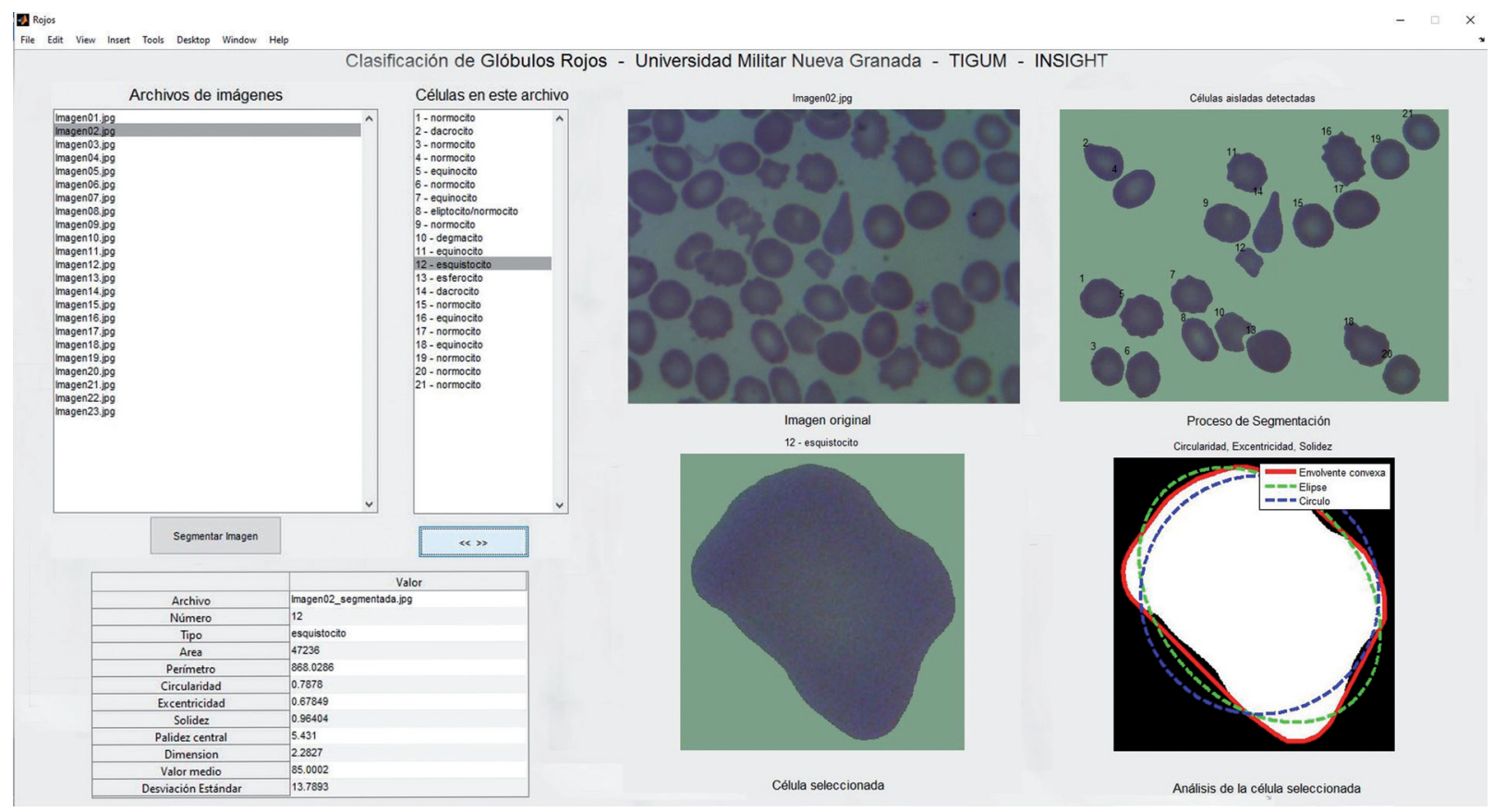

Figura 6. Interfaz gráfica de la herramienta desarrollada

Al comparar la clasificación obtenida automáticamente con la clasificación realizada por los expertos, se observa que la aplicación logra clasificar certeramente j, el $97.3 \%$ del total de las células. Sin embargo cabe resaltar que las células que no fueron adecuadamente clasificadas presentan características morfológicas comunes a más de un tipo de eritrocito, con lo cual su clasificación presenta problemas de reproducibilidad y 
objetividad desde la forma de evaluación convencional, confundiendo también a los expertos. Así por ejemplo, el eritrocito de la derecha en la Figura 4 presenta simultáneamente características de dacrocito, equinocito y eliptocito, de tal forma que aunque en este caso el experto la clasificó como un equinocito, otro experto fácilmente la hubiera podido clasificar como un eliptocito, por ejemplo. Además se requiere un entrenamiento de la red con el apoyo de expertos en esta área para mejorar los resultados y poder aplicar eficazmente el software.

Cabe anotar que en una imagen de frotis de sangre periférica puede haber leucocitos y trombocitos además de eritrocitos, aunque su presencia no dificulta la clasificación de glóbulos rojos porque los leucocitos (neutrófilos, linfocitos T ó B, monocitos macrófagos, eosinófilos y basófilos) son células nucleadas que varían entre ocho y $14 \mathrm{~m}$ de diámetro y son mucho menos comunes en la sangre (cerca de un leucocito por cada 600 eritrocitos) mientras que los trombocitos son fragmentos de citoplasma de dos a tres $\mathrm{mm}$ de diámetro, con cerca de un trombocito por cada 20 eritrocitos y, en consecuencia, no es difícil distinguir los eritrocitos de los leucocitos y los trombocitos ${ }^{1}$. Al calcular el área y el perímetro de las regiones así detectadas, se puede determinar cuáles de ellas podrían corresponder a eritrocitos y, así, es posible eliminar la mayoría de trombocitos, leucocitos y formas inmaduras de eritrocitos. De esta manera también eliminamos la mayoría de rollos y aglutinaciones. Sin embargo, cuando los rollos están compuestos por dos eritrocitos superpuestos, pueden tener tamaños semejantes a un eritrocito grande, por lo que se estableció un "tipo" de eritrocito, el rollo, para detectar esta condición.

De otro lado, las redes neuronales artificiales se han utilizado exitosamente en diferentes campos de aplicación donde se requiera llevar a cabo procesos de reconocimiento, identificación, detección, estimación y clasificación, cuando no existen relaciones cerradas entre las variables de entrada y de salida que permitan un tratamiento analítico clásico ${ }^{10}$. En nuestro caso, la combinación de procesamiento digital de imágenes y redes neuronales ha resultado muy conveniente para el problema de clasificación propuesto, pues la información discriminante que se encuentra en las características seleccionadas es altamente compleja para algún otro tipo de tratamiento.

Para próximos trabajos se propone avanzar en el proceso de segmentación para lograr aislar eritrocitos ligeramente superpuestos y utilizar otras características como las relaciones de color para extender el conjunto de clases de eritrocitos que el sistema puede detectar, incluyendo la detección de cuerpos de Howell-Jolly y otros componentes importantes para el diagnóstico clínico.

\section{AGRADECIMIENTOS}

Producto derivado del proyecto ING-1532, financiado por la Vicerrectoría de Investigaciones de la Universidad Militar Nueva Granada - Vigencia 2014. Agradecemos el apoyo del personal científico y administrativo de la Universidad Militar Nueva Granada, el Hospital Militar Central y el Centro de Investigaciones de la Clínica del Country en este proyecto.

\section{CONFLICTOS DE INTERÉS}

Los autores declaran no tener conflictos de interés.

\section{REFERENCIAS}

1. Carr J, Rodak B. Atlas de hematología clínica. Bogotá: Editorial médica panamericana; 2011.

2. Naranjo C. Atlas de hematología células sanguíneas. Segunda edición, Manizales: Centro de publicaciones Universidad Católica de Manizales; 2008.

3. Carr J, Rodak B. Atlas de hematología Clínica. Tercera edición, Buenos Aires: Editorial Médica Panamericana; 2010.

4. Campuzano Maya G. Utilidad clínica del extendido de sangre periférica: los eritrocitos. Med Laboratorio. 2008;14(7-8): 311-357.

5. Mohammed EA, Mohamed MMA, Far BH y Naugler C. Peripheral blood smear image analysis: a comprehensive review. J Pathol Inform. 2014; 5(1): 60-69. DOI: 10.4103/2153-3539.129442.

6. Micheli-Tzanakou E, Sheikh H, Zhu B. Neural networks and blood cell identification. J. Med Syst. 1997; 21(4): 201-210.

7. Khashman A. Blood cell identification using a simple neural network. Int J Neural Syst. 2008; 18(5): 453-458.

8. Bergen T1, Steckhan D, Wittenberg T, Zerfass T. Segmentation of leukocytes and erythrocytes in blood smear images. Conf Proc IEEE Eng Med Biol Soc. 2008; 2008: 3075-3078. DOI: 10.1109/ IEMBS.2008.4649853.

9. Lee H, Chen. Y. Cell morphology based classification for red cells in blood smear images. Patt Recogn Letters. 2014; 49: 155-161. DOI: 10.1016/j. patrec.2014.06.010.

10. Razali T, Wan Nurshazwani WZ, Muhammad 
Mahadi AJ, Faridah MN, Nik Farhan NF. Computer aided system for red blood cell classification in blood smear image. Procedia Computer Science. 2014; 42: 206-213.

11. Gual-Arnau X, Herold-García S, Simón A. Erythrocyte shape classification using integralgeometry-based methods, Med Biol Eng Comput. 2015; 53(7): 623-633. DOI: 10.1007/s11517-015$1267-\mathrm{x}$.

12. Wheeless LL, Robinson RD, Lapets OP, Cox C, Rubio A, Weintraub M, et al. Classification of red blood cells as normal, sickle, or other abnormal, using a single image analysis feature. Cytometry. 1994; 17(2): 159-166.

13. Oliveros E, Domínguez S, García P, Fernández M, Fernández K. Clasificación automatizada de eritrocitos en imágenes de muestras de sangre periféricas. IX Congreso Internacional de Informática en la Salud. Habana. Cuba; 2013.

14. Poon SS, Ward RK, Palcic B. Automated image detection and segmentation in blood smears. Cytometry. 1992; 13(7): 766-774.

15. Savkare SS, Narote SP. Automatic system for classification of erythrocytes infected with Malaria and identification of parasite's life stage. Procedia Technology. 2012; 6: 405-410. DOI: 10.1016/j. protcy.2012.10.048.

16. Rezatofighi SH, Soltanian-Zadeh H. Automatic recognition of five types of white blood cells in peripheral blood. Comput Med Imaging Graph. 2011; 35(4): 333-343. DOI: 10.1016/j. compmedimag.2011.01.003.

17. Albertini MC, Teodori L, Piatti E, Piacentini M, Accorsi A, Rocchi M. Automated analysis of morphometric parameters for accurate definition of erythrocyte cell shape. Cytometry. 2003; 52A(1): 12-18.

18. MATLAB Release 2012b, The MathWorks, Inc., Natick, Massachusetts, United States. 2015.

19. Mejía Fajardo M, Monroy Alzate M. Clasificación de formas patológicas de eritrocitos humanos. Ingeniería. 2016; 21(1): 31-48

20. Gonzalez C, Woods R. Digital image processing. $3^{\text {rd }}$ edition. Upper Saddle River, New Jersey: Pearson Prentice Hall; 2008.

21. Jian L, Qian D, Caixin S. An improved box-counting method for image fractal dimension estimation. Pattern Recogn. 2009; 42(11): 2460-2469. DOI: 10.1016/j.patcog.2009.03.001.

22. Haykin S. Neural Networks and Learning Machines. New York: Prentice Hall. 2008.

23. Fawcett T. An introduction to ROC analysis. Pattern Recognition Letters. 2006; 27: 861-874. 